\title{
Stranski-Krastanov Mode in Iron Electrodeposition
}

\author{
M. Saitou \\ Department of Mechanical Systems Engineering, University of the Ryukyus, 1 Senbaru Nishihara-cho \\ Okinawa, 903-0213, Japan \\ E-mail: saitou@tec.u-ryukyu.ac.jp
}

doi: $10.20964 / 2017.03 .25$

Received: 9 Decemebr 2016 / Accepted: 6 January 2017 / Published: 12 February 2017

The morphological transition of iron thin films generated by a rectangular pulse current technique having a frequency ranging from 0.1 to $1 \mathrm{MHz}$ was investigated using scanning electron microscope (SEM) and X-ray diffraction (XRD). An increase in the film thickness of the iron thin film grown on an ITO glass was found to cause two types of the Stranski-Krastanov (S-K) mode: the forward S-K mode that the two-dimensional growth changes into the three dimensional growth first appeared, and the reverse $\mathrm{S}-\mathrm{K}$ mode that the three dimensional growth changes into the two-dimensional growth secondly appeared. A critical film thickness at which the S-K mode transition occurs was several orders of magnitude larger than that reported in vapor phase epitaxy. In addition, an increase in the deposition temperature also caused the reverse S-K mode. XRD analysis revealed that the S-K mode took place owing to the competition between the dominant (211) plane and the (110) plane. The iron thin film composed of only the (211) plane parallel to the ITO glass was generated.

Keywords: forward Stranski-Krastanov, reverse Stranski-Krastanov, iron thin film, critical film thickness

\section{$\underline{\text { FULL TEXT }}$}

(C) 2017 The Authors. Published by ESG (www.electrochemsci.org). This article is an open access article distributed under the terms and conditions of the Creative Commons Attribution license (http://creativecommons.org/licenses/by/4.0/). 